\title{
P Wave Abnormality by ECG Finding
}

National Cancer Institute

\section{Source}

National Cancer Institute. P Wave Abnormality by ECG Finding. NCI Thesaurus. Code C90430.

An electrocardiographic finding for the P wave that is atypical either for the shape, duration, amplitude, axis or polarity. Abnormality of the $\mathrm{P}$ wave signifies aberrant propagation of the electrical impulse through the atria. 